\title{
H/D Exchange of Gas Phase Bradykinin Ions in a Linear Quadrupole Ion Trap
}

\author{
Dunmin Mao and D. J. Douglas \\ Department of Chemistry, University of British Columbia, Vancouver, British Columbia, Canada
}

\begin{abstract}
The gas phase H/D exchange reaction of bradykinin ions, as well as fragment ions of bradykinin generated through collisions in an orifice skimmer region, have been studied with a linear quadrupole ion trap (LIT) reflectron time-of-flight (rTOF) mass spectrometer system. The reaction in the trap takes only tens of seconds at a pressure of few mTorr of $\mathrm{D}_{2} \mathrm{O}$ or $\mathrm{CD}_{3} \mathrm{OD}$. The exchange rate and hydrogen exchange level are not sensitive to the trapping $\mathrm{q}$ value over a broad range, provided $\mathrm{q}$ is not close to the stability boundary $(\mathrm{q}=0.908)$. The relative rates and hydrogen exchange levels of protonated and sodiated +1 and +2 ions are similar to those observed previously by others with a Fourier transform ion cyclotron resonance (FTICR) mass spectrometer system. The doubly and triply protonated ions show multimodal isotopic distributions, suggesting the presence of several different conformations. The $y$ fragment ions show greater exchange rates and levels than a or b ions, and when water or ammonia is lost from the fragment ions, no exchange is observed. (J Am Soc Mass Spectrom 2003, 14, 85-94) (c 2003 American Society for Mass Spectrometry
\end{abstract}

W ith the development of electrospray ionization (ESI) and matrix-assisted laser desorption and ionization (MALDI), the structures of proteins and other biomolecular ions in the absence of solvent have become of interest. As indicated in reviews by Clemmer and coworkers [1] and Jarrold [2], techniques for investigating the gaseous ion structures can be grouped into two categories: physical probes such as cross section measurements and ion dissociation, and chemical probes involving ion-molecule reactions.

H/D exchange, a method widely used to study protein conformation in solution, has also been used to study the structures of gas phase ions. Protons are replaced by deuterons through ion molecule reactions between ions and neutral reagents, such as $\mathrm{D}_{2} \mathrm{O}$, $\mathrm{CD}_{3} \mathrm{OD}$ or $\mathrm{ND}_{3}$. From a study of glycine oligomer ions $\left(\mathrm{Gly}_{\mathrm{n}}, \mathrm{n}=1-5\right)$, Beauchamp and coworkers proposed several mechanisms of $\mathrm{H} / \mathrm{D}$ exchange in the gas phase [3]. Reagents with greater proton affinity such as $\mathrm{ND}_{3}$ gain a proton from the $\mathrm{N}$-terminus and are solvated by the peptide ("onium" mechanism), while those with lower proton affinity, such as $\mathrm{D}_{2} \mathrm{O}$, gain deuterium and lose hydrogen simultaneously (relay mechanism). Although the mechanisms of H/D exchange in the gas phase for large systems are not as well established as in solution, by analogy to solution exchange $[4,5]$, it is

Published online January 6, 2003

*Address reprint requests to Dr. D. J. Douglas, Department of Chemistry, University of British Columbia, 2036 Main Mall, Vancouver, BC, V6T 1Z1,

Canada. E-mail: douglas@chem.ubc.ca plausible that more tightly folded states will exchange lower numbers of hydrogens than more open unfolded states. Exchangeable hydrogens exposed on an ion surface are expected to be replaced faster than those buried inside an ion. Although the relation between folding and exchange level is uncertain, different exchange levels and exchange rates likely indicate different conformations.

To date, H/D exchange of gaseous ions has been done mostly with FTICR systems where ions are confined at very low pressures [6-14]. A deuterating reagent is added at a pressure of $10^{-7}$ to $10^{-5}$ torr, and exchange takes place on a time scale from minutes to hours. H/D exchange of small ions in quadrupole ion traps has also been reported [15-19]. Hofstadler et al. showed that $\mathrm{H} / \mathrm{D}$ exchange could be observed for ions confined in a linear hexapole field with $\mathrm{D}_{2} \mathrm{O}$ or $\mathrm{ND}_{3}$ at a pressure of about $10^{-6}$ torr [20]. In the first experiments the exchange time was not well defined because exchange and accumulation occurred simultaneously [20a]. In later experiments the ions were trapped with well defined exchange times [20b]. The hexapole exit potential was set to prevent ions from being transmitted to an FTICR and ions exchanged for periods from zero up to $60 \mathrm{~s}$. Recently, Witt et al. described the H/D exchange of several peptide ions in a modified hexapole trap coupled to an ICR cell. The hexapole was used as an ion guide to collisionally cool ions generated by MALDI [21]. Ions were trapped for up to $60 \mathrm{~s}$ when $\mathrm{D}_{2} \mathrm{O}$ or $\mathrm{CD}_{3} \mathrm{OD}$ vapor was infused into the trap. Although the ICR was maintained at $10^{-6}-10^{-7}$ torr, the pressure in the trap was not well determined. 


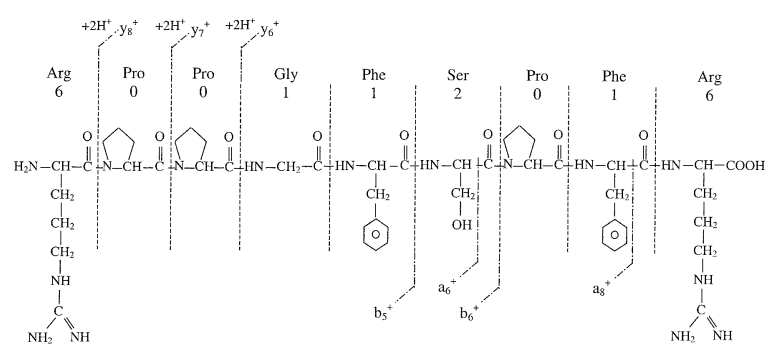

Figure 1. Structure of bradykinin. Listed below the amino acid residues are the numbers of exchangeable hydrogens in the residue. The fragments shown were observed in the mass spectrum (Figure 4).

Ions of bradykinin (BK, Arg-Pro-Pro-Gly-Phe-Ser-ProPhe-Arg, Figure 1) are among the most extensively studied gaseous peptide ions. Cross section measurements show that singly and doubly protonated bradykinin ions $\left(\mathrm{BK}+\mathrm{nH}^{+}, \mathrm{n}=1,2\right)$ and the sodiated ions $\left(\mathrm{BK}+\mathrm{Na}^{+}\right)$have almost the same size [22-24], while the triply protonated ions $\left(\mathrm{BK}+3 \mathrm{H}^{+}\right)$have cross sections ca. $15 \%$ greater [24, 25]. Wyttenbach et al. found in molecular dynamics simulations that both guanidine groups of the two arginine residues in the $\mathrm{BK}+\mathrm{H}^{+}$and $\mathrm{BK}+\mathrm{Na}^{+}$ions are strongly involved in binding the positive charge and that the carboxyl groups of the backbone are coordinated to the charge site [23] to form globular ions wrapped around the charge center. Williams and coworkers studied the blackbody infrared dissociation (BIRD) of singly and doubly protonated bradykinin ions and several of their analogues [26, 27]. The dominant product of the BK + $\mathrm{H}^{+}$ion is the $\mathrm{BK}+\mathrm{H}^{+}-\mathrm{NH}_{3}$ fragment, while $\mathrm{b}_{2}^{+} / \mathrm{y}_{7}^{+}$ ions are the major products of the $\mathrm{BK}+2 \mathrm{H}^{+}$ion. The BIRD spectra and Arrhenius activation parameters for singly protonated ions support a tightly folded ion conformation where the ion surrounds the protonation site to solvate the charge. They suggested that the most stable form of the singly protonated ion has a salt bridge with the interaction of the deprotonated Cterminal carboxylate group with protonated side chains of the two arginine residues [26]. Although the most likely protonation sites of the doubly protonated species are the two basic arginine residues, molecular dynamics simulations indicated that the charge on the $\mathrm{N}$-terminal arginine side chain is solvated by the backbone carbonyl oxygen at the second proline which results in the major $b_{2}^{+} / y_{7}^{+}$ions in the BIRD experiment. Ion dissociation in a quadrupole ion trap showed the same dissociation pathways as the BIRD experiments for the singly and doubly protonated species [28]. However $\mathrm{BK}+2 \mathrm{H}^{+}-\mathrm{H}_{2} \mathrm{O}$ ions were also observed from the $\mathrm{BK}+2 \mathrm{H}^{+}$ions and a water loss dominated the $\mathrm{BK}+3 \mathrm{H}^{+}$ion dissociation. The triply protonated ion was found to dissociate much more rapidly than the singly and doubly charged ions. Gimon-Kinsel et al. studied the post-source decay of bradykinin and its analogues on a MALDI-TOF mass spectrometer system and proposed two gross conformations of $\mathrm{BK}+\mathrm{H}^{+}$ ions [29]. In addition to the intramolecular hydrogen bond proposed by Williams and coworkers [26, 27], intramolecular hydrogen bonds between the hydroxyl group of the serine residue and the protonated guanidine group of the C-terminal arginine were proposed.

Gas phase H/D exchange has been used to study bradykinin ions. High hydrogen exchange levels of $\mathrm{BK}+\mathrm{H}^{+}$with $\mathrm{D}_{2} \mathrm{O}$ in an early FTICR experiment are believed to be due to ion heating from quadrupolar axialization [30, 31]. Green et al. found that doubly charged bradykinin ions showed a greater exchange rate than singly charged ions with $10^{-7}$ torr of $\mathrm{CH}_{3} \mathrm{OD}$ and with up to 13 minutes of storage in an ICR cell [10]. Freitas and Marshall studied H/D exchange of bradykinin ions in an ICR cell with storage times up to one hour at $10^{-5}$ torr of $\mathrm{D}_{2} \mathrm{O}[9,11]$. The $\mathrm{H} / \mathrm{D}$ exchange levels varied widely among the +1 and +2 parent ions, sodium adduct ions and their analogues; the results were consistent with a zwitterion form for the protonated bradykinin ions [11]. McLuckey and coworkers studied the $\mathrm{H} / \mathrm{D}$ exchange of $\mathrm{BK}+2 \mathrm{H}^{+}$and $\mathrm{BK}+3 \mathrm{H}^{+}$ ions in a quadrupole ion trap with $\mathrm{D}_{2} \mathrm{O}$ and DI $[17,18]$ The $\mathrm{BK}+3 \mathrm{H}^{+}$ions showed the presence of two reactive populations, as evidenced by a bimodal isotopic distribution $[17,18]$, while $\mathrm{BK}+\mathrm{H}^{+}$ions showed only one [17]. Levy-Seri et al. performed H/D exchange with $\mathrm{ND}_{3}$ or $\mathrm{CH}_{3} \mathrm{OD}$ in a flow-tube [32] to obtain site specific rate constants. It was proposed that the first three replaced hydrogens are equivalent and are at the protonated N-terminus amine group. Recently, Purves et al. found four conformers of $\mathrm{BK}+2 \mathrm{H}^{+}$ions with a combination of $\mathrm{H} / \mathrm{D}$ exchange and high-field asymmetric waveform ion mobility spectrometry (FAIMS) [33]. The hydrogen exchange level of $\mathrm{BK}+2 \mathrm{H}^{+}$ions formed by MALDI [21] was found to be same as that for BK + $2 \mathrm{H}^{+}$ions formed by ESI, observed in an ICR cell [11].

In this paper, we describe a study of the H/D exchange reactions of bradykinin ions confined in a LIT. Bradykinin was chosen because its H/D exchange has been well studied previously, and this allows an assessment of the use of a linear quadrupole ion trap to study $\mathrm{H} / \mathrm{D}$ exchange. Because the partial pressure of deuterating reagent can be ca. $10^{-3}$ to $10^{-2}$ torr, orders of magnitude higher than in ICR experiments $\left(10^{-7}\right.$ to $10^{-5}$ torr), the exchange can take place in seconds. The experiments demonstrate that the linear ion trap is well suited to the study of ion-molecule reactions with ions stored for up to $100 \mathrm{~s}$. The hydrogen exchange levels of ions of bradykinin ( $\left.\mathrm{BK}+\mathrm{nH}^{+}, \mathrm{n}=1-3\right)$, bradykinin fragments, and sodium adduct ions, with $\mathrm{D}_{2} \mathrm{O}$ and $\mathrm{CD}_{3} \mathrm{OD}$, were obtained with well defined exchange times. The relative exchange rates and levels for the +1 and +2 parent ions and the sodium adduct ions are comparable to the results of FTICR and 3-D ion trap experiments. The exchange level is much lower for the singly protonated ions compared to the doubly charged and sodiated ions. The $\mathrm{BK}+2 \mathrm{H}^{+}$ions show a bimodal isotopic distribution in exchange with $\mathrm{D}_{2} \mathrm{O}$ and a trimodal distribution in exchange with $\mathrm{CD}_{3} \mathrm{OD}$, suggesting 


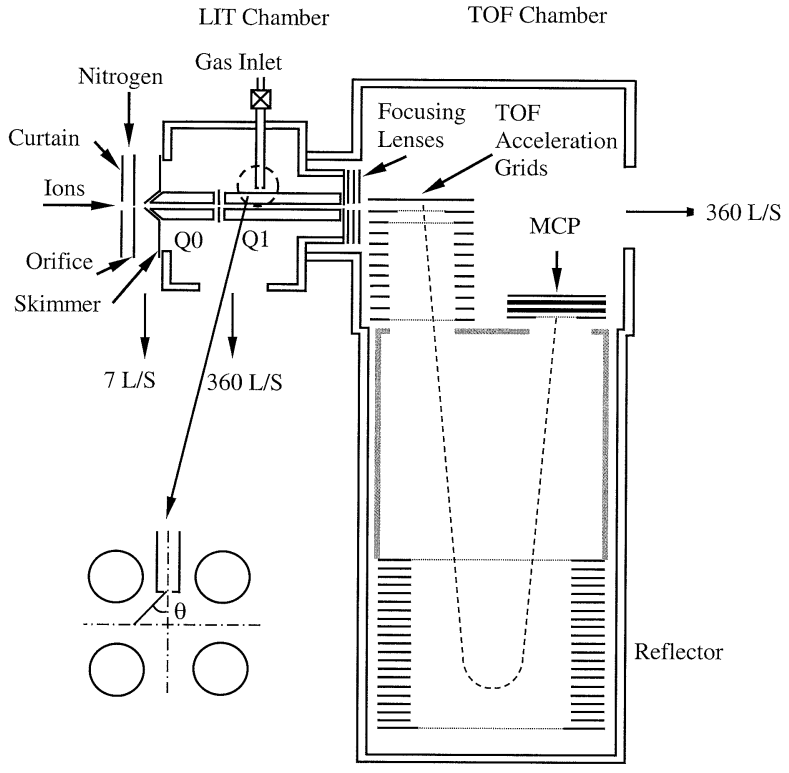

Figure 2. A diagram of the linear quadrupole ion trap and reflectron time-of-flight mass spectrometer system.

there are several different conformations for these ions. New results are presented for $\mathrm{H} / \mathrm{D}$ exchange of the $\mathrm{y}_{6}^{+}, \mathrm{y}_{7}^{+}, \mathrm{y}_{8}^{+}, \mathrm{y}_{8}^{2+}, \mathrm{a}_{6}^{+}, \mathrm{a}_{8}^{+}$, and $\mathrm{b}_{6}^{+}$and $\mathrm{b}_{8}^{+}$ions. The $\mathrm{y}$ ions have higher exchange rates and levels than the $a$ or $b$ ions, and when water or ammonia is lost from the fragment ions, no exchange is observed.

\section{Experimental}

Experiments were performed with a LIT rTOF mass spectrometer system (Figure 2), described previously $[34,35]$. Ions, generated by pneumatically assisted electrospray, pass through a dry nitrogen "curtain" gas, an orifice, a skimmer (orifice skimmer voltage difference $\left.\Delta \mathrm{V}_{\mathrm{os}}=150 \mathrm{~V}\right)$ and enter a chamber containing two RF-only quadrupoles, Q0 and Q1 (typical rod offsets 12.5 and $10 \mathrm{~V}$, respectively). The curtain gas prevents air and solvent from entering the vacuum system and no evidence for back exchange with solvents [20b] or charge stripping was found. The region between the orifice and skimmer is evacuated to a background pressure of $\sim 2$ torr by a rotary pump (Leybold Trivac D16A, Export, PA). Quadrupole Q1 is operated as a linear ion trap. Ions are confined radially by the RF potentials (frequency $768 \mathrm{kHz}$ ) on the quadrupole, and axially by timed DC stopping potentials applied to the entrance and exit aperture plates. Unless otherwise stated, ions were trapped with an RF voltage of $514 \mathrm{~V}_{p-p}$ pole to ground. The corresponding Mathieu parameters were $\mathrm{q}=0.477$ and $\mathrm{q}=0.239$ for $\mathrm{BK}+2 \mathrm{H}^{+}$and $\mathrm{BK}+$ $\mathrm{H}^{+}$ions, respectively. Ions then leave the trap through a stack of lenses, and enter the acceleration region of an orthogonally coupled reflectron TOF-MS (SCIEX, Concord, ON, Canada). For mass analysis, ions are extracted into the flight tube by a series of acceleration pulses and monitored by a dual microchannel plate
(MCP) detector (40 mm diameter, Galileo Electro-Optics Corporation, Sturbridge, MA). Signals from the MCP are amplified (Model 774 preamplifier, Phillips Scientific, Ramsey, NJ), acquired by a time-to-digital converter (TDC $\times 4$, Ionwerks, Houston, TX) and stored in a computer.

Typically, the pressures in the LIT and TOF chambers are maintained as low as $1.6 \mathrm{mTorr}$ of nitrogen and $4.0 \times 10^{-7}$ torr, respectively, by $360 \mathrm{~L} / \mathrm{s}$ turbomolecular pumps (Turbovac 361, Leybold) backed by rotary pumps (7 L/s, D16A, Leybold Export, PA). Deuterating reagent, $\mathrm{D}_{2} \mathrm{O}$ or $\mathrm{CD}_{3} \mathrm{OD}$, flows continuously into $\mathrm{Q} 1$ through a $0.9 \mathrm{~mm}$ diameter nozzle, $4 \mathrm{~mm}$ radially out from the center of the trap, to form a free jet. The H/D exchange takes place with the reagent in the free jet and also with background reagent that fills the chamber. The latter makes the greater contribution to the exchange, as illustrated here for $\mathrm{D}_{2} \mathrm{O}$. The number density, $n$, of the reagent in the free jet [36] is given approximately by

$$
\frac{n}{n_{0}}=0.0615 \cos ^{2}(0.832 \theta)\left(\frac{a}{D_{0}}\right)^{-2}
$$

where $\mathrm{n}_{0}$ is the number density in the nozzle, $\theta$ is the angle shown in the inset of Figure 2, a is the distance between the nozzle and the point of interest in the trap and $\mathrm{D}_{0}$ is the nozzle diameter $(0.9 \mathrm{~mm})$. Typically, the $\mathrm{D}_{2} \mathrm{O}$ pressure inside the nozzle is about 7 torr $\left(\mathrm{n}_{0}=\right.$ $2.3 \times 10^{17} \mathrm{~cm}^{-3}$ ). Calculation of the density distribution from eq 1 shows that the $\mathrm{D}_{2} \mathrm{O}$ forms a free jet with a locally high density over a ca. $40 \mathrm{~mm}$ region of Q1 with a maximum number density of $7.5 \times 10^{14} \mathrm{~cm}^{-3}$ (equivalent to a pressure of $23 \mathrm{mTorr}$ ). Integrating eq 1 gives a number density, averaged over the length of Q1, equivalent to an average pressure of 0.85 mTorr. This is relatively low compared to the background pressure of $\mathrm{D}_{2} \mathrm{O}, 5.7 \mathrm{mTorr}$. The effective pressure in the trap is the sum of the contributions from the free jet and background, or 6.6 mTorr in this case. Unless otherwise stated, all experiments were done with a background pressure of deuterating agent of 5.7 mTorr. This background pressure was chosen as a compromise between two effects. At lower pressures, the exchange takes longer. At higher pressures, the background pressure in the TOF chamber rises and this degrades the mass resolution.

The timing sequence for the ion storage and TOF acquisition is controlled by an arbitrary waveform generator (AWG-344, PC Instruments Inc., Akron, OH) which triggers home-made power supplies for the trap entrance and exit plates, as well as a pulse generator (Model 500, Berkeley Nucleonics, San Rafael, CA) to control the TOF-MS detection. Typical low/high voltages on the entrance and exit plates are $+10.5 \mathrm{~V} /+31 \mathrm{~V}$ and $-10 \mathrm{~V} /+34 \mathrm{~V}$, respectively. The timing parameters are given in Figure 3. Each trapping cycle contains four segments: Ion drain, ion injection, trapping, and ion 


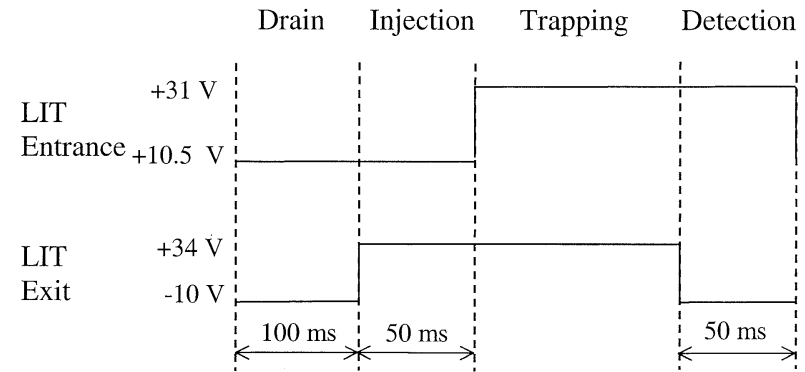

Figure 3. Timing sequence and voltages on the entrance and exit plates of the linear quadrupole ion trap in a trapping cycle.

detection. Ions continuously accumulate in $\mathrm{Q} 0$ when the ion trap entrance voltage is $+31 \mathrm{~V}$ during the trapping and detection periods. These ions can exchange with the background deuterating reagent and do not have well defined reaction times. They are eliminated in the first phase of each cycle by keeping both the trap entrance and exit plates at low voltages for $100 \mathrm{~ms}$ to allow Q0 to drain to low levels of ions. For ion injection, the voltage on the trap entrance plate remains low $(+10.5 \mathrm{~V})$ for $50 \mathrm{~ms}$, while a stopping potential of $+34 \mathrm{~V}$ is applied to the exit plate. Ions are confined in Q1 by increasing the trap entrance plate to $+31 \mathrm{~V}$ and maintaining the exit plate at $+34 \mathrm{~V}$. H/D exchange occurs mainly during this period. After ions have been trapped for a given period, they are mass analyzed in the TOF-MS system. Typically, 166 acceleration pulses of $30 \mu$ s width at a repetition frequency of $3333 \mathrm{~Hz}$ are applied for $50 \mathrm{~ms}$. The system was mass calibrated with ions of bradykinin ( $\left.\mathrm{BK}+\mathrm{H}^{+}, \mathrm{n}=1-3\right)$, reserpine $(\mathrm{M}+$ $\left.\mathrm{H}^{+}\right)$and $\left[\mathrm{Glu}^{1}\right]$-fibrinopeptide $\left(\mathrm{M}+2 \mathrm{H}^{+}\right)$.

Bradykinin (B3259, $\mathrm{mw}=1060.2)$, $\left[\mathrm{Glu}^{1}\right]$-fibrinopeptide $(\mathrm{F} 3261, \mathrm{mw}=1570.6)$, and reserpine $(\mathrm{R} 0875, \mathrm{mw}=$ 608.7) were from Sigma Chemical Co. (St. Louis, MO). Solutions for ESI were: (1) $0.1 \mathrm{mM}$ bradykinin in 50/50 deionized water/methanol (HPLC grade, Fisher Scientific, Fair Lawn, NJ) with $3 \mathrm{mM}$ ammonium acetate (crystalline, certified ACS, Fisher Scientific), (2) $30 \mu \mathrm{M}$ [Glu ${ }^{1}$ ]-fibrinopeptide in 50/50 deionized water/methanol, and (3) $10 \mu \mathrm{M}$ reserpine in acetonitrile (HPLC grade, Fisher Scientific) with $10 \mathrm{mM}$ ammonium acetate. Deuterium oxide $\left(99.9 \%\right.$ D) and methanol- $\mathrm{d}_{4}$ $(99.8 \% \mathrm{D})$ were from Cambridge Isotope Laboratories, Inc. (Andover, MA).

\section{Results and Discussion}

The mass spectrum of bradykinin obtained with the LIT-rTOF-MS system and without trapping is shown in Figure 4. Three types of ions can be identified: (1) protonated and sodiated molecular ions, $\mathrm{BK}+\mathrm{H}^{+}$, $\mathrm{BK}+2 \mathrm{H}^{+}, \mathrm{BH}+\mathrm{Na}^{+}$, and $\mathrm{BK}+\mathrm{H}^{+}+\mathrm{Na}^{+}$; (2) fragment ions, $\mathrm{y}_{\mathrm{n}}^{+}(\mathrm{n}=6-8), \mathrm{y}_{8}^{2+}, \mathrm{a}_{8}^{+}, \mathrm{a}_{6}^{+}, \mathrm{b}_{6}^{+}$, and $\mathrm{b}_{5}^{+}$; (3) ions formed from neutral losses, $\mathrm{BK}+2 \mathrm{H}^{+}-\mathrm{NH}_{3}, \mathrm{~b}_{6}^{+}-$ $\mathrm{H}_{2} \mathrm{O} / \mathrm{b}_{6}^{+}-\mathrm{NH}_{3}, \mathrm{a}_{8}^{+}-\mathrm{NH}_{3}$, and $\mathrm{y}_{8}^{+}-\mathrm{H}_{2} \mathrm{O} / \mathrm{y}_{8}^{+}-\mathrm{NH}_{3}$. The fragment ions are produced through collisional

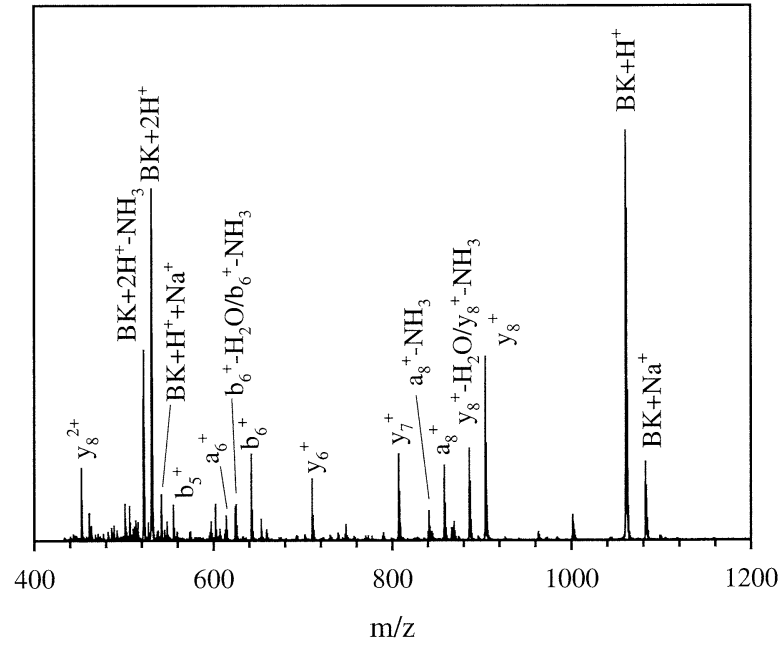

Figure 4. Mass spectrum of bradykinin obtained at a background pressure of $1.6 \mathrm{mTorr}$ of nitrogen, $\mathrm{V}_{\mathrm{RF}}=514 \mathrm{~V}_{p-p}$ (pole-to-ground) and $\Delta \mathrm{V}_{\mathrm{os}}=150 \mathrm{~V}$.

activation in the orifice skimmer region. Due to the overlap of the isotopic peaks, the losses of $\mathrm{NH}_{3}$ and $\mathrm{H}_{2} \mathrm{O}$ from fragment ions could not be distinguished. $\mathrm{H} / \mathrm{D}$ exchange of all of these ions will be described. Although additional ions were observed, some of them lost intensity at long trapping times possibly due to further fragmentation (e.g., $\mathrm{y}_{5}^{+}$) or their isotopic envelopes overlapped (e.g., $\mathrm{BK}+2 \mathrm{H}^{+}-\mathrm{NH}_{3}$ and $\mathrm{a}_{5}^{+}$). Interpretation of results for these ions is ambiguous and they are not discussed.

\section{H/D Exchange of Protonated and Sodiated Adduct Molecular Ions}

The mass spectra of $\mathrm{BK}+2 \mathrm{H}^{+}$and $\mathrm{BK}+\mathrm{H}^{+}$ions trapped for up to $80 \mathrm{~s}$ in $5.7 \mathrm{mTorr}$ of $\mathrm{D}_{2} \mathrm{O}$ are shown in Figure 5 . Figure $5 \mathrm{a}$ and $5 \mathrm{~g}$ were obtained by introducing nitrogen to keep the total pressure of the trap chamber constant during the time of recording spectra. When $\mathrm{D}_{2} \mathrm{O}$ was introduced to the trap, weaker features on the high mass side of the $\mathrm{BK}+2 \mathrm{H}^{+}$isotopic envelope were observed with $0 \mathrm{~s}$ of trapping (Figure $5 b)$. This indicates that some H/D exchange occurred. Even without additional trapping, the trap is filled for $50 \mathrm{~ms}$, so that ions have between 0 and $50 \mathrm{~ms}$ to exchange before entering the TOF. As the storage time increases, more isotopic structure appears on the high mass side and the isotopic envelope expands (Figure 5c, $5 \mathrm{~d})$. A bimodal isotopic distribution of the $\mathrm{BK}+2 \mathrm{H}^{+}$ ions can be identified at $1 \mathrm{~s}$ of storage (Figure 5c). A bimodal distribution was not reported in the quadrupole ion trap study of Schaaff et al., possibly because of the relatively small exchange level that was possible in that experiment (limited by formation of DI adducts) [17]. The exchange rate constants of Freitas et al. showed a distribution of 3 slow exchanges and 16 fast exchanges for these ions, although a bimodal isotopic distribution was not described [11]. Although less struc- 


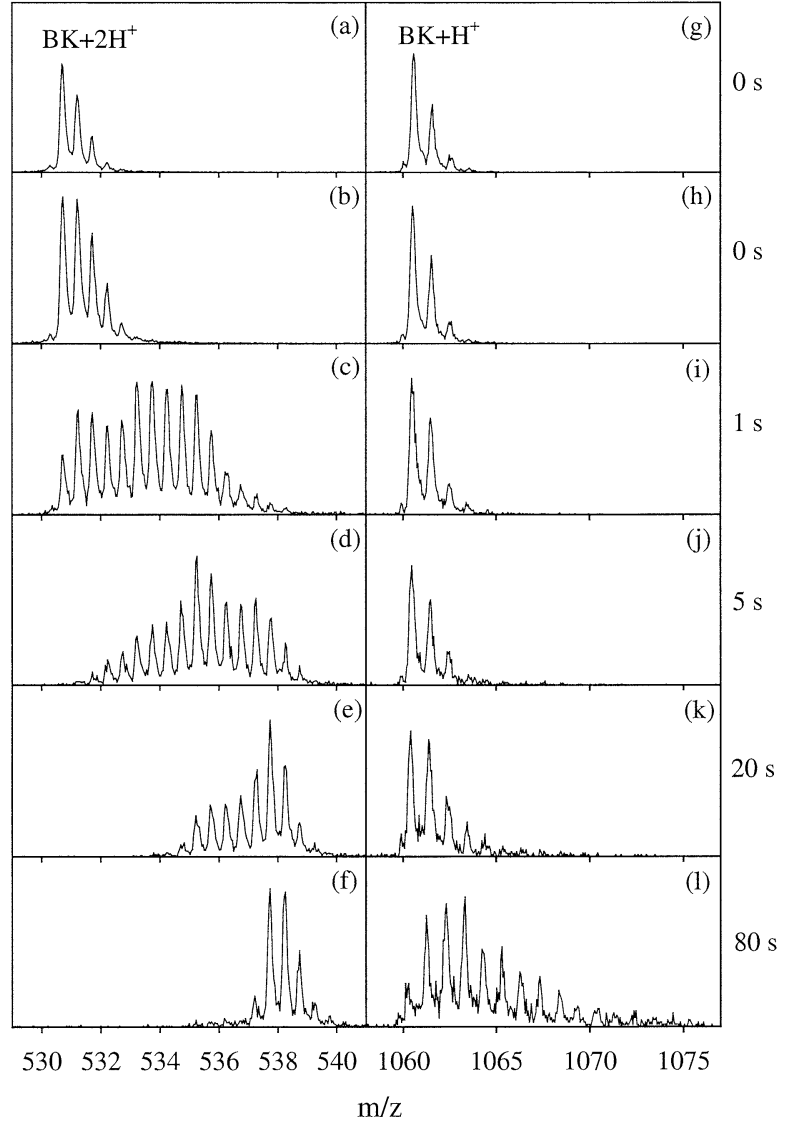

Figure 5. Mass spectra of doubly- $(\mathbf{a}-\mathbf{f})$ and singly- $(\mathbf{g}-\mathbf{1})$ protonated bradykinin ions at different ion storage times, listed on the right of the figure. (a) and $(\mathrm{g})$ were recorded with 8.5 mTorr of nitrogen in the LIT chamber while all others were obtained with 2.8 mTorr base pressure of nitrogen and $5.7 \mathrm{mTorr}$ of $\mathrm{D}_{2} \mathrm{O}$ in the trap chamber.

ture appears after $20 \mathrm{~s}$ of storage, it takes an additional $60 \mathrm{~s}$ for the isotopic envelope to become as simple as that of Figure 5a. Ions stored $100 \mathrm{~s}$ do not exhibit further exchange.

The $\mathrm{BK}+\mathrm{H}^{+}$ions show much slower exchange (Figure 5h-1). Additional isotopic structure can be observed only after $20 \mathrm{~s}$ of trapping. The reaction shows no sign of completion even at $100 \mathrm{~s}$ of trapping. In addition, only a single modal isotopic distribution is observed.

Two different mechanisms have been distinguished in studying the H/D exchange of proteins in solution [5, 37-40]. Proteins with two conformers that interconvert slowly relative to the exchange rate and exchange at different rates in solution will show two peaks or isotopic distributions in a mass spectrum (EX1 mechanism). If the two conformers intercovert rapidly relative to the rate of exchange a single peak is expected (EX2 mechanism). If these considerations can be applied to gas phase $\mathrm{H} / \mathrm{D}$ exchange, the bimodal distribution of the $\mathrm{BK}+2 \mathrm{H}^{+}$isotopic envelope can be attributed to at least two different conformations in the gas phase, while only one conformer of the $\mathrm{BK}+\mathrm{H}^{+}$ions is identified with $100 \mathrm{~s}$ of trapping. However it is also

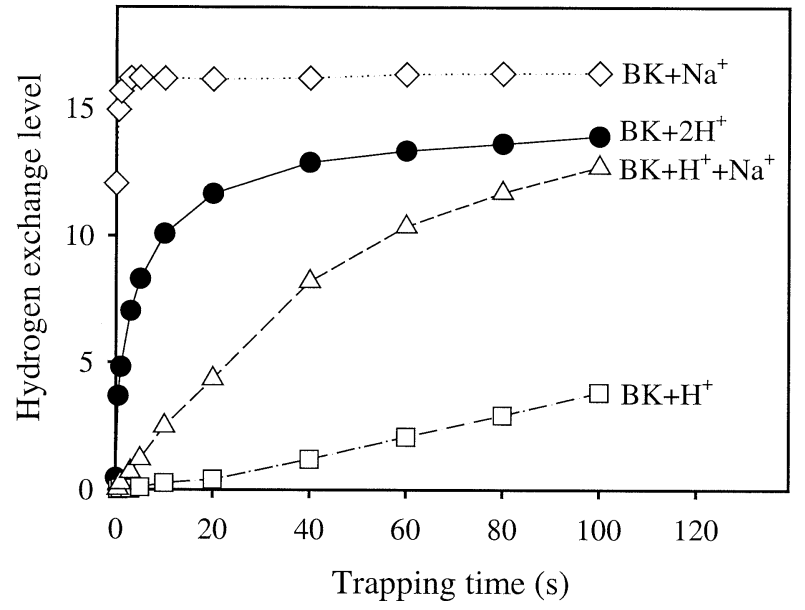

Figure 6. Hydrogen exchange levels versus trapping time for BK $+2 \mathrm{H}^{+}$(filled circles), $\mathrm{BK}+\mathrm{H}^{+}$(open squares), $\mathrm{BK}+\mathrm{H}^{+}+\mathrm{Na}^{+}$ (open triangles), and $\mathrm{BK}+\mathrm{Na}^{+}$(open diamonds).

possible that the $\mathrm{BK}+\mathrm{H}^{+}$ions have several conformations that interconvert rapidly relative to the slower (seconds) time scale of the exchange. Interestingly, ion mobility studies [24] show the opposite behavior: A single conformation for the $\mathrm{BK}+2 \mathrm{H}^{+}$ions and at least three conformations for the $\mathrm{BK}+\mathrm{H}^{+}$ion.

These mass spectra illustrate an important issue for the study of $\mathrm{H} / \mathrm{D}$ exchange of large ions. If the individual isotopic peaks are ignored, the isotopic envelope is relatively narrow before the reaction occurs. As the $\mathrm{H} / \mathrm{D}$ exchange proceeds, the isotopic envelope first broadens. It then narrows when the reaction is complete. For large ions, like proteins [41], the resolving power of the mass spectrometer may not be sufficient to obtain isotopic structure. However, the change of the envelope of the isotopic peaks during the H/D exchange process can provide some less detailed information about the reaction.

At a certain exchange level, each of the initial isotopic peaks will produce its own isotopic distribution, due to multiple exchange levels. An average hydrogen exchange level can be obtained from the difference of the average molecular weight (amw) with and without exchange, where

$$
a m w=\left(\sum_{i} \frac{I_{i}(m / z)_{i}}{\sum_{j} I_{j}}\right) z
$$

Here, $\mathrm{I}_{\mathrm{i}}$ and $(\mathrm{m} / \mathrm{z})_{\mathrm{i}}$ are the intensity and mass-to-charge ratio of the isotopic peak $\mathrm{i}$ with charge $\mathrm{z}$. The hydrogen exchange levels of four ions, $\mathrm{BK}+\mathrm{H}^{+}, \mathrm{BK}+2 \mathrm{H}^{+}$, BK $+\mathrm{Na}^{+}$, and $\mathrm{BK}+\mathrm{H}^{+}+\mathrm{Na}^{+}$at trapping times up to $100 \mathrm{~s}$ are shown in Figure 6. As noted by Green and Lebrilla [10], although ion mobility experiments show that $\mathrm{BK}+2 \mathrm{H}^{+}, \mathrm{BK}+\mathrm{H}^{+}$and $\mathrm{BK}+\mathrm{Na}^{+}$ions have similar cross sections [23, 24], these ions show quite different behavior in H/D exchange. Under the conditions here, after $100 \mathrm{~s}$ the doubly charged $\mathrm{BK}+2 \mathrm{H}^{+}$ 
ions exchange 14 of 19 exchangeable hydrogens (exchange percentage $74 \%$ ), while on average 4 of 18 exchangeable hydrogens in singly charged $\mathrm{BK}+\mathrm{H}^{+}$ ions are replaced (exchange percentage $22 \%$ ). The sodium adduct molecular ions show the opposite trend. The singly charged $\mathrm{BK}+\mathrm{Na}^{+}$ions have 16 hydrogens rapidly incorporated (exchange percentage $96 \%$ ), while the doubly charged $\mathrm{BK}+\mathrm{H}^{+}+\mathrm{Na}^{+}$ions have 13 hydrogens replaced (exchange percentage $72 \%$ ). In addition, the doubly charged $\mathrm{BK}+2 \mathrm{H}^{+}$ions exchange faster than the singly charged $\mathrm{BK}+\mathrm{H}^{+}$ions, while the singly charged $\mathrm{BK}+\mathrm{Na}^{+}$ions exchange much faster than the doubly charged $\mathrm{BK}+\mathrm{H}^{+}+\mathrm{Na}^{+}$ions. The relative rates and exchange levels of $\mathrm{BK}+\mathrm{H}^{+}, \mathrm{BK}+$ $\mathrm{Na}^{+}$, and $\mathrm{BK}+2 \mathrm{H}^{+}$agree well with those observed in an ICR cell by Freitas et al. [11]. This experiment, at $100 \mathrm{~s}$, shows higher absolute exchange levels of BK + $\mathrm{H}^{+}$ions than the ICR experiments [11]. The difference can be attributed to the greater numbers of collisions in the trap used here, determined by the product of number density and trapping time. The pressure of $\mathrm{D}_{2} \mathrm{O}$ in the FTICR experiment of Freitas et al. was $1.0 \times 10^{-5}$ torr, and ions were stored for up to $1 \mathrm{~h}$ (3600 s) [11] to give a product of number density and time of $1.2 \times 10^{15}$ $\mathrm{cm}^{-3} \mathrm{~s}$. In the experiment here, the product of the number density $\left(2.2 \times 10^{14} \mathrm{~cm}^{-3}\right)$ and the storage time $(100 \mathrm{~s})$ is $2.2 \times 10^{16} \mathrm{~cm}^{-3} \mathrm{~s}$. The number of collisions in the linear trap experiment is about 20 times greater. Therefore, higher exchange levels can be observed for slow reactions. Similarly, the lowest rate constant that can be measured for a single reaction step is approximately the inverse of the density-time product, or $\mathrm{k}=$ $8.3 \times 10^{-16} \mathrm{~cm}^{3} \mathrm{~s}^{-1}$ in the ICR cell and $\mathrm{k}=4.5 \times 10^{-17}$ $\mathrm{cm}^{3} \mathrm{~s}^{-1}$ in the LIT, respectively. To observe a process with this rate constant in the ICR experiment at a pressure of $1 \times 10^{-5}$ torr would require ion storage for about twenty hours.

While the results of Figure 6 are in good qualitative agreement with the ICR results of Freitas et al., the BK $+\mathrm{H}^{+}+\mathrm{Na}^{+}$ions in this experiment show somewhat different behavior. In the ICR experiment, at the intermediate time of about $0.43 \mathrm{~h}$, where $\mathrm{BK}+2 \mathrm{H}^{+}$ions exchanged 12 hydrogens on average, the BK + $\mathrm{H}^{+}+\mathrm{Na}^{+}$ions exchange less than one [11]. In the experiment here, when $\mathrm{BK}+2 \mathrm{H}^{+}$ions have exchanged 12 hydrogens, after about $23 \mathrm{~s}$ (Figure 6), the BK + $\mathrm{H}^{+}+\mathrm{Na}^{+}$ions have exchanged about five hydrogens. The reasons for this difference are not understood. It is possible the $\mathrm{BK}+\mathrm{H}^{+}+\mathrm{Na}^{+}$ions are activated to a greater extent in the ion sampling interface used here, and thus unfold to less protected structures. It is also possible that the ions can refold to more compact structures on the much longer time scale of the ICR experiment.

\section{Trapping at Different $q$ Values}

Trapping of ions in a quadrupole field involves a competition between heating of ions by the RF field,

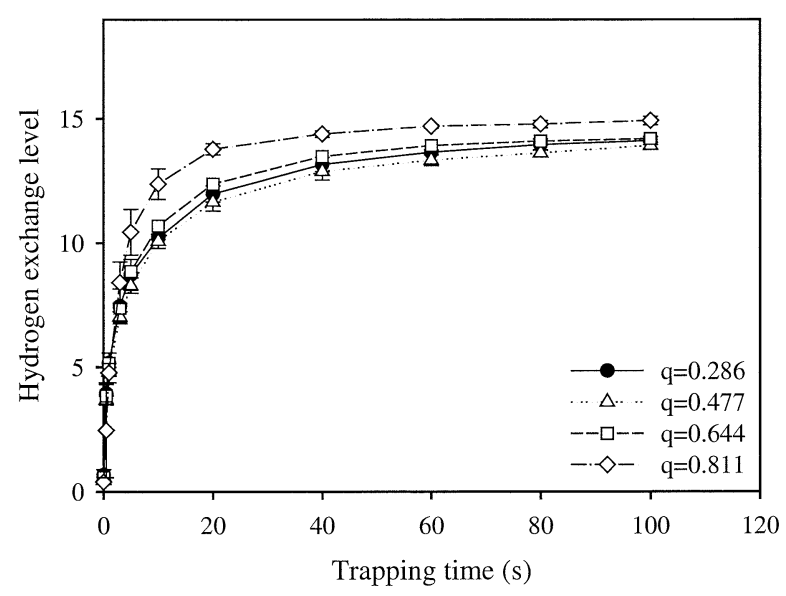

Figure 7. Hydrogen exchange levels of $\mathrm{BK}+2 \mathrm{H}^{+}$versus the trapping time at $\mathrm{q}=0.286$ (filled circles), 0.477 (open triangles), 0.644 (open squares), and 0.811 (open diamonds).

and cooling by the bath gas. The temperature of trapped ions may depend on the trapping RF level, or Mathieu parameter $\mathrm{q}$, where

$$
q=\frac{2 e V_{p-p}}{m r_{0}^{2}(2 \pi f)^{2}}
$$

Here $\mathrm{V}_{p-p}$ is the pole-to-ground peak-to-peak RF voltage, $r_{0}$ is the field radius of the linear quadrupole and $f$ is the RF frequency. If ions are heated by the RF field in these experiments, the conformation of the peptide ions might shift to higher energy structures and the intrinsic reaction rate could change. The effect of the trapping voltage on the four ions of Figure 6 was investigated, and results from the $\mathrm{BK}+2 \mathrm{H}^{+}$ions are presented in Figure 7. The exchange rate and the levels do not change significantly at $\mathrm{q} \leq 0.64$, while both show a slight increase at $\mathrm{q}=0.811, \mathrm{a} \mathrm{q}$ value close to the stability boundary $(\mathrm{q}=0.908)$. The $\mathrm{BK}+\mathrm{H}^{+}+\mathrm{Na}^{+}$ ions, which have similar $q$ values, showed a similar effect. The singly charged ions had q values less than 0.41 in all the experiments and no differences in exchange rates were seen at the different $q$ values. Overall, the exchange levels and rates are insensitive to the $q$ value at which ions are stored, provided $\mathrm{q}$ is not near the stability boundary where $\mathrm{q}=0.908$.

This does not necessarily mean that the ions in the trap have the same temperatures at all $\mathrm{q}$ values less than 0.64 . For heavy ions in a light gas, the reaction rate will be insensitive to the distribution of ion kinetic energies. The reaction rate is determined by the distribution of collision energies in centre of mass coordinates. If the ions and gas have different kinetic temperatures, the collision energy distribution in the centre of mass coordinate is described by an effective temperature, $\mathrm{T}_{\text {eff }}$, given by [42].

$$
\frac{T_{e f f}}{\mu}=\frac{T_{1}}{m_{1}}+\frac{T_{2}}{m_{2}}
$$


where $T_{1}$ is the ion temperature, $T_{2}$ is the gas temperature, $m_{1}$ is the ion mass, $m_{2}$ is the gas mass, and $\mu$ is the reduced mass $\left(\mu=\mathrm{m}_{1} \mathrm{~m}_{2} /\left(\mathrm{m}_{1}+\mathrm{m}_{2}\right)\right)$. If the bradykinin ions, for example, have a temperature of $1000 \mathrm{~K}$, and the $\mathrm{D}_{2} \mathrm{O} 295 \mathrm{~K}$, the effective temperature is calculated to be $\mathrm{T}_{\text {eff }}=308 \mathrm{~K}$ and this determines the reaction rate. Thus, for heavy ions, $\mathrm{T}_{\text {eff }}$ is relatively insensitive to the ion temperature and mainly determined by the gas temperature. Asano et al. have shown that dissociation rate constants of bradykinin $\left(\mathrm{BK}+\mathrm{H}^{+}, \mathrm{n}=1-3\right)$ [28] and leucine enkephalin [43] ions confined in a 3-D trap do not depend on the $\mathrm{q}$ value at $\mathrm{q}<0.4$. In addition, they used a model by Blatt et al. [44] to calculate the temperature of leucine enkephalin buffered by helium in a quadrupole ion trap [43]. Their calculations showed that the effective temperature of the ion is essentially equal to the temperature of the bath gas at low q values. When $q$ is close to the stability boundary, internal excitation is expected and an increase of ion temperature induces an increase of the effective temperature. This increase is used in boundary activated dissociation (BAD), where ions are stored near the stability boundary to induce dissociation [45-50].

\section{Results with $\mathrm{CD}_{3} \mathrm{OD}$}

Figure 8 shows the mass spectra of $\mathrm{BK}+2 \mathrm{H}^{+}$and $\mathrm{BK}+$ $\mathrm{H}^{+}$ions trapped for various times in 5.7 mTorr of $\mathrm{CD}_{3} \mathrm{OD}$. Clearly the two ions show different behavior from that with $\mathrm{D}_{2} \mathrm{O}$ at the same pressure (Figure 5). For the doubly charged $\mathrm{BK}+2 \mathrm{H}^{+}$ions, more isotopic structure on the high mass side is observed with $0 \mathrm{~s}$ of trapping, indicating that the initial exchange rate is greater with $\mathrm{CD}_{3} \mathrm{OD}$. Instead of a bimodal isotopic distribution, as seen with $1 \mathrm{~s}$ of trapping with $\mathrm{D}_{2} \mathrm{O}$ in Figure $5 c$, a trimodal isotopic distribution is observed. If the EX1 mechanism [37-39] applies, the trimodal isotopic distribution corresponds to at least three conformers of the $\mathrm{BK}+2 \mathrm{H}^{+}$ions. These may be similar to the four conformers seen in the FAIMS experiments [33]. The mass spectra of the singly charged $\mathrm{BK}+\mathrm{H}^{+}$ions trapped with $\mathrm{CD}_{3} \mathrm{OD}$ in Figure $8 \mathrm{~g}-1$ are similar to those with $\mathrm{D}_{2} \mathrm{O}$ in Figure $5 \mathrm{~g}-1$ except that more isotopic peaks are observed after $20 \mathrm{~s}$ of trapping. The exchange rate with $\mathrm{CD}_{3} \mathrm{OD}$ is greater. With both $\mathrm{D}_{2} \mathrm{O}$ and $\mathrm{CD}_{3} \mathrm{OD}, \mathrm{BK}$ $+\mathrm{H}^{+}$ions show single mode isotopic distributions at all trapping times.

The average hydrogen exchange levels of $\mathrm{BK}+2 \mathrm{H}^{+}$ and $\mathrm{BK}+\mathrm{H}^{+}$ions with $\mathrm{D}_{2} \mathrm{O}$ and $\mathrm{CD}_{3} \mathrm{OD}$ versus the trapping time are shown in Figure 9. The initial reaction rate (up to $3 \mathrm{~s}$ ) of the $\mathrm{BK}+2 \mathrm{H}^{+}$ions with $\mathrm{CD}_{3} \mathrm{OD}$ is greater than that with $\mathrm{D}_{2} \mathrm{O}$. The slowest reacting population of the $\mathrm{BK}+2 \mathrm{H}^{+}$ions has a greater abundance with $\mathrm{CD}_{3} \mathrm{OD}$ than with $\mathrm{D}_{2} \mathrm{O}$ at $\sim 1 \mathrm{~s}$ of trapping. This decreases the overall average reaction rate at longer trapping times. At $100 \mathrm{~s}$, the hydrogen exchange level with $\mathrm{CD}_{3} \mathrm{OD}$ is slightly less than that of $\mathrm{D}_{2} \mathrm{O}$. The lower exchange level of $\mathrm{BK}+2 \mathrm{H}^{+}$with $\mathrm{CD}_{3} \mathrm{OD}$ compared to $\mathrm{D}_{2} \mathrm{O}$ was first observed by Witt et al. when ions were

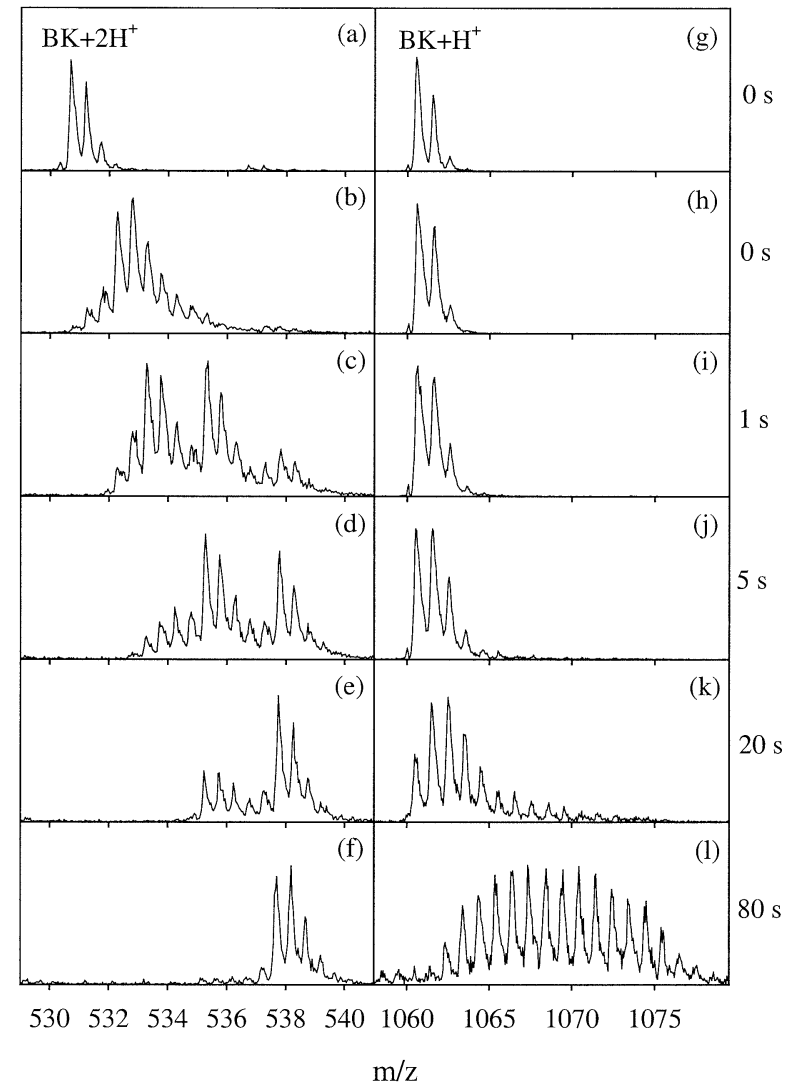

Figure 8. Mass spectra of doubly- (a-f) and singly- (g-1) protonated bradykinin ions with different storage times, listed to the right of the figure. (a) and (g) were recorded with 7.4 mTorr of nitrogen in the LIT chamber while all others were recorded with a 1.7 mTorr base pressure of nitrogen and 5.7 mTorr of $\mathrm{CD}_{3} \mathrm{OD}$ in the trap chamber.

confined in a modified hexapole trap [21]. However, for $\mathrm{BK}+\mathrm{H}^{+}$ions, both the exchange rate and thus the hydrogen exchange levels are increased with $\mathrm{CD}_{3} \mathrm{OD}$. The higher proton affinity of $\mathrm{CD}_{3} \mathrm{OD}(181.9 \mathrm{kcal} / \mathrm{mol})$ than $\mathrm{D}_{2} \mathrm{O}(166.5 \mathrm{kcal} / \mathrm{mol})$ may imply a different exchange mechanism that increases the exchange rate at short trapping times.

\section{H/D Exchange of Fragment Ions}

As shown in Figure 4, some fragment ions were generated in the orifice skimmer region. The H/D exchange reactions of these ions were also investigated. Figure 10 shows the hydrogen exchange levels of $a, b$, and $y$ ions at trapping times up to $100 \mathrm{~s}$. Among the singly charged ions, $y$ ions exchange faster than $\mathrm{a}$ and $\mathrm{b}$ ions, and their hydrogen exchange levels are also greater after $100 \mathrm{~s}$ of trapping. This indicates that hydrogens are more protected in $\mathrm{a}$ and $\mathrm{b}$ ions than in $\mathrm{y}$ ions. If it is assumed that the charge is on the arginine residues in these ions, the two arginines show quite different behavior. These observations are consistent with ICR experiments where a higher exchange rate and exchange level were observed with des-arg ${ }^{1}$-bradykinin $+\mathrm{H}^{+}$(similar to $\mathrm{y}$ 


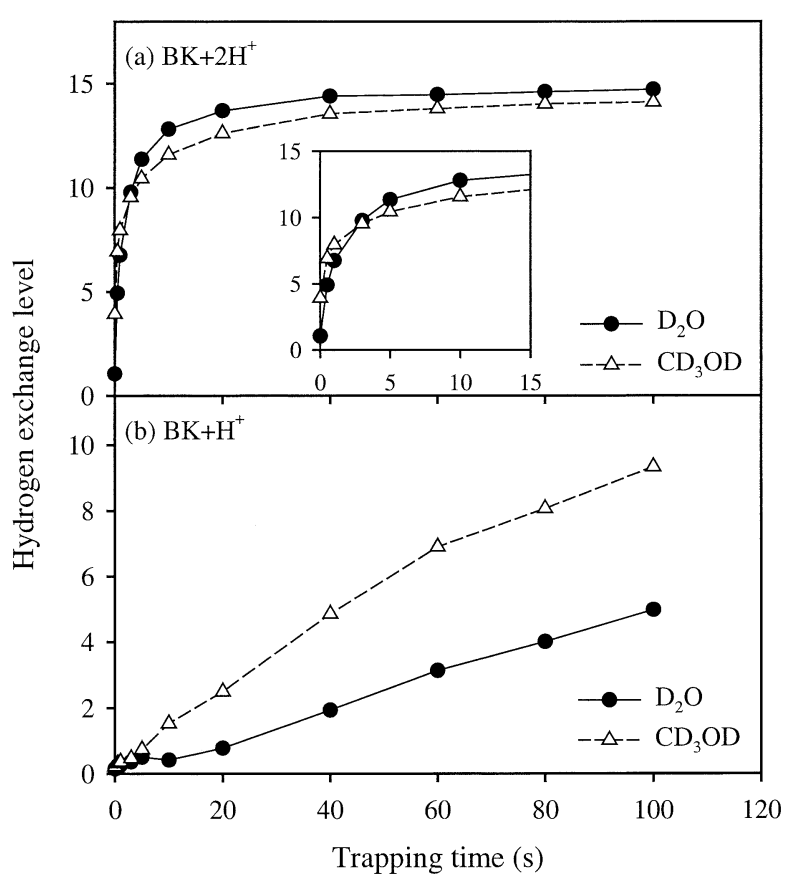

Figure 9. Hydrogen exchange levels of (a) $\mathrm{BK}+2 \mathrm{H}^{+}$and (b) $\mathrm{BK}$ $+\mathrm{H}^{+}$ions versus the trapping time with $\mathrm{D}_{2} \mathrm{O}$ (filled circles) and $\mathrm{CD}_{3} \mathrm{OD}$ (open triangles).

ions) than with des-arg 9 -bradykinin $+\mathrm{H}^{+}$(similar to $\mathrm{b}$ ions) $[9,11]$. Fragment ions with a neutral loss $\left(b_{6}^{+}-\right.$ $\mathrm{H}_{2} \mathrm{O} / \mathrm{b}_{6}^{+}-\mathrm{NH}_{3}, \mathrm{a}_{8}^{+}-\mathrm{NH}_{3}$, and $\mathrm{y}_{8}^{+}-\mathrm{H}_{2} \mathrm{O} / \mathrm{y}_{8}^{+}-\mathrm{NH}_{3}$ ) showed no hydrogen exchange after $100 \mathrm{~s}$ of trapping (results not shown). This indicates that loss of a neutral molecule can induce substantial structural changes which makes hydrogens more protected, or that the hydrogens in the lost neutral molecule contribute to the observed exchanged hydrogens in their precursor ions. No multimodal isotopic distributions were observed with fragment ions.

\section{$H / D$ Exchange of $B K+3 H^{+}$Ions}

Triply charged bradykinin ions, $\mathrm{BK}+3 \mathrm{H}^{+}$, have greater cross sections than $\mathrm{BK}+\mathrm{H}^{+}$or $\mathrm{BK}+2 \mathrm{H}^{+}$ions [22-25]. Therefore, greater exchange levels might be expected. In order to generate $\mathrm{BK}+3 \mathrm{H}^{+}$ions, $1 \%$ acetic acid was added to the 50/50 water/methanol solvent. This gave a weak $\mathrm{BK}+3 \mathrm{H}^{+}$ion signal, about $5 \%$ and $10 \%$ of the doubly and singly charged ions respectively. The RF voltage was decreased to $308 \mathrm{~V}_{p-p}$ to lower the low mass cut-off of the trap $\left(\mathrm{q}=0.429\right.$ for $\mathrm{BK}+3 \mathrm{H}^{+}$ ions). Results of $\mathrm{H} / \mathrm{D}$ exchange with $\mathrm{D}_{2} \mathrm{O}$ for trapping times up to $20 \mathrm{~s}$ are shown in Figure 11. At short trapping times $(<5 \mathrm{~s})$, the exchange rate of the $\mathrm{BK}+$ $3 \mathrm{H}^{+}$ions is greater than $\mathrm{BK}+2 \mathrm{H}^{+}$and $\mathrm{BK}+\mathrm{H}^{+}$, as might be expected from the cross section measurements. A bimodal isotopic distribution of $\mathrm{BK}+3 \mathrm{H}^{+}$ ions was observed (results not shown), as with BK + $2 \mathrm{H}^{+}$ions, indicating that there are at least two reactive populations. A bimodal distribution was also seen by

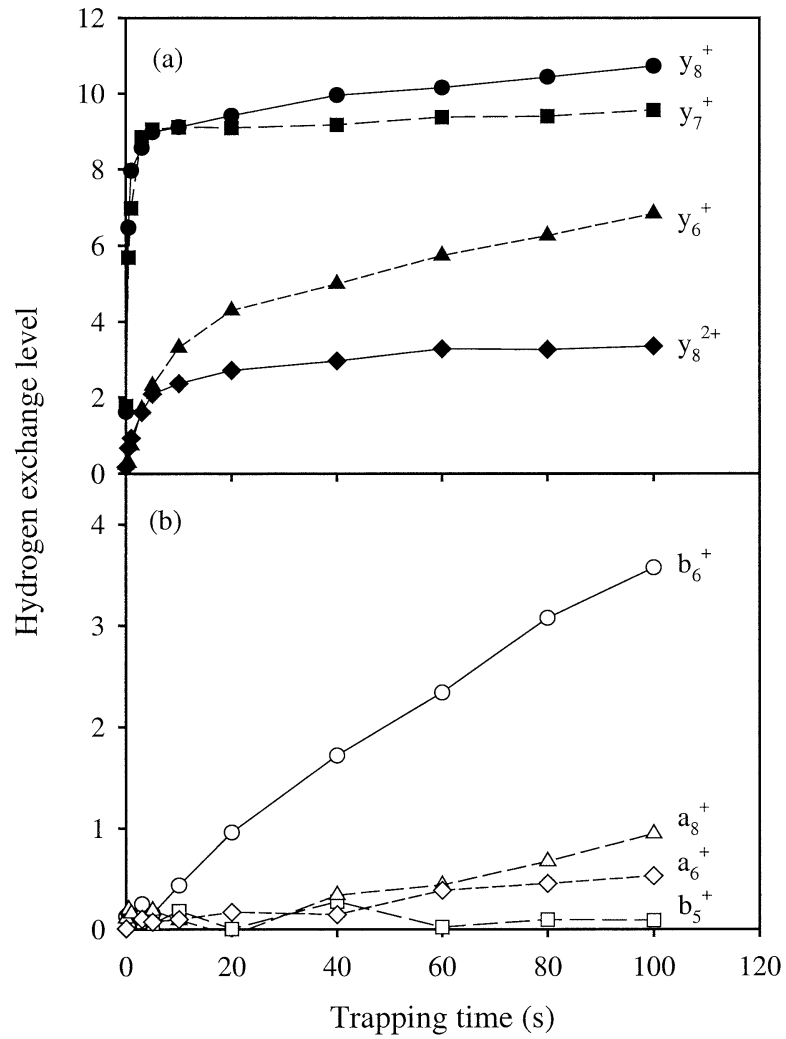

Figure 10. Hydrogen exchange levels of bradykinin fragment ions versus trapping time. (a) $\mathrm{y}_{8}^{+}$(filled circles), $\mathrm{y}_{7}^{+}$(filled squares), $\mathrm{y}_{6}^{+}$(filled triangles), and $\mathrm{y}_{8}^{2+}$ (filled diamonds); (b) $\mathrm{b}_{6}^{+}$(open circles), $b_{5}^{+}$(open squares), $a_{8}^{+}$(open triangles), and $a_{6}^{+}$(open diamonds).

Schaaff et al. $[17,18]$. The slowly reacting population is a greater fraction of the ions than with $\mathrm{BK}+2 \mathrm{H}^{+}$ causing a decrease in the overall reaction rate at $20 \mathrm{~s}$ of trapping, relative to $\mathrm{BK}+2 \mathrm{H}^{+}$ions.

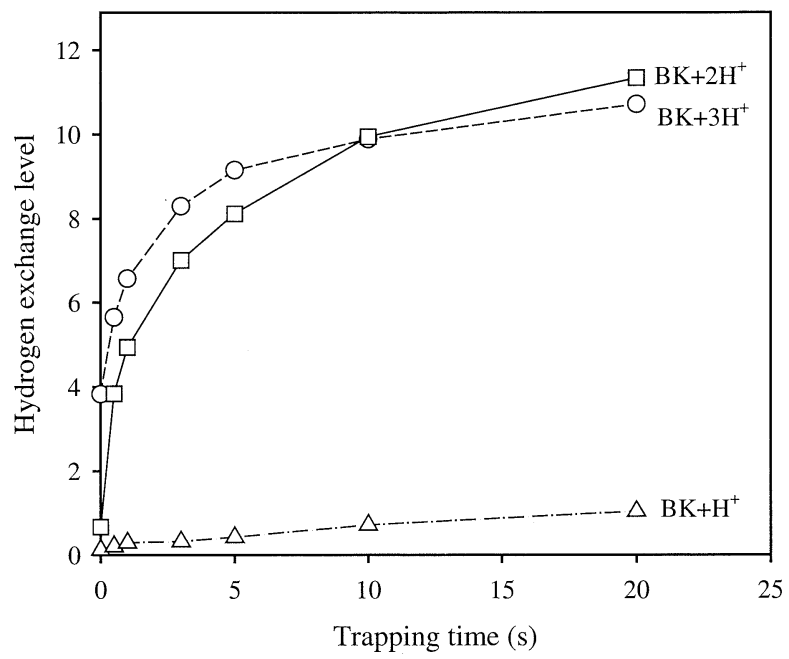

Figure 11. Hydrogen exchange levels versus trapping time for $\mathrm{BK}+3 \mathrm{H}^{+}$(open circles), $\mathrm{BK}+2 \mathrm{H}^{+}$(open squares), and $\mathrm{BK}+\mathrm{H}^{+}$ (open triangles). The partial pressure of $\mathrm{D}_{2} \mathrm{O}$ in the trap chamber was 5.7 mTorr and the RF voltage on the quadrupole was $308 \mathrm{~V}_{p-p}$ (pole-to-ground). 


\section{Summary}

Results here are generally in agreement with earlier experiments with FTICR or quadrupole ion traps. Multimodal distributions were observed here for the BK + $2 \mathrm{H}^{+}$ions for the first time. First observations of H/D exchange of fragment ions show that the y fragments have greater exchange levels than a and $b$ fragments, and that when small neutrals are lost from these ions, no exchange is observed. Considerable modelling may be necessary to understand the structures of these gas phase ions.

The results here demonstrate that this LIT-rTOF-MS system can be used to study H/D exchange reactions at mTorr pressures of deuterating reagent. Due to the much greater deuterating reagent pressure in the LIT, the same degree of exchange takes place in seconds, compared to hours in an ICR cell. This makes the linear quadrupole ion trap more suitable for the study of slow exchange reactions.

\section{Acknowledgments}

This work was supported through a Natural Sciences and Engineering Research Council Research Grant and a Natural Sciences and Engineering Research Council-SCIEX Industrial Research Chair.

\section{References}

1. Hoaglund-Hyzer, C. S.; Counterman, A. E.; Clemmer, D. E. Anhydrous Protein Ions. Chem. Rev. 1999, 99, 3037-3079.

2. Jarrold, M. F. Peptides and Proteins in the Vapor Phase. Ann. Rev. Phys. Chem. 2000, 51, 179-207.

3. Campbell, S.; Rodgers, M. T.; Marzluff, E. M.; Beauchamp, J. L. Deuterium Exchange Reactions as a Probe of Biomolecule Structure. Fundamental Studies of Gas Phase H/D Exchange Reactions of Protonated Glycine Oligomers with $\mathrm{D}_{2} \mathrm{O}$, $\mathrm{CD}_{3} \mathrm{OD}, \mathrm{CD}_{3} \mathrm{CO}_{2} \mathrm{D}$, and $\mathrm{ND}_{3}$. J. Am. Chem. Soc. 1995, 117, 12840-12854.

4. Katta, V.; Chait, B. T. Conformational Changes in Proteins Probed by Hydrogen-Exchange Electrospray-Ionization Mass Spectrometry. Rapid Commun. Mass Spectrom. 1991, 5, 214-217.

5. Eagen, J. R.; Smith, D. L. Investigating Protein Structure and Dynamics by Hydrogen Exchange MS. Anal. Chem. 2001, 73, 256A-265A.

6. Suckau, D.; Shi, Y.; Beu, S. C.; Senko, M. W.; Quinn, J. P.; Wampler, F.M., III; McLafferty, F. W. Coexisting Stable Conformations of Gaseous Protein Ions. Proc. Natl. Acad. Sci. U.S.A. 1993, 90, 790-793.

7. Wood, T. D.; Chorush, R. A.; Wampler, F. W., III; Little, D. P.; O'Conner, P. B.; McLafferty, F. W. Gas-Phase Folding and Unfolding of Cytochrome $c$ Cations. Proc. Natl. Acad. Sci. U.S.A. 1995, 92, 2451-2454.

8. McLafferty, F. W.; Guan, Z.; Haupts, U.; Wood, T. D.; Kelleher, N. L. Gaseous Conformational Structures of Cytochrome $c$. J. Am. Chem. Soc. 1998, 120, 4732-4740.

9. Freitas, M. A.; Hendrickson, C. L.; Emmett, M. R.; Marshall, A. G. High-Field Fourier Transform Ion Cyclotron Resonance Mass Spectrometry for Simultaneous Trapping and Gas Phase Hydrogen/Deuterium Exchange of Peptide Ions. J. Am. Soc. Mass Spectrom. 1998, 9, 1012-1019.

10. Green, M. K.; Lebrilla, C. B. The Role of Proton-Bridged Intermediates in Promoting Hydrogen-Deuterium Exchange in Gas Phase Protonated Diamines, Peptides, and Proteins. Int. J. Mass Spectrom. Ion Proc. 1998, 175, 15-26.

11. Freitas, M. A.; Marshall, A. G. Rate and Extent of Gas Phase Hydrogen/Deuterium Exchange of Bradykinins: Evidence for Peptide Zwitterions in the Gas Phase. Int. J. Mass Spectrom. 1999, 182/183, 221-231.

12. Freitas, M. A.; Hendrickson, C. L.; Emmett, M. R.; Marshall, A. G. Gas-Phase Bovine Ubiquitin Cation Conformation Resolved by Gas-Phase Hydrogen/Deuterium Exchange Rate and Extent. Int. J. Mass Spectrom. 1999, 185/186/187, 565-575.

13. Green-Church, K. B.; Limbach, P. A.; Freitas, M. A.; Marshall, A. G. Gas-Phase Hydrogen/Deuterium Exchange of Positively Charged Mononucleotides by Use of Fourier-Transform Ion Cyclotron Resonance Mass Spectrometry. J. Am. Soc. Mass Spectrom. 2001, 12, 268-277.

14. Solouki, T.; Fort, R.C., Jr.; Alomary, A.; Fattahi, A. Gas Phase Hydrogen Deuterium Exchange Reactions of a Model Peptide: FT-ICR and Computational Analyses of Metal Induced Conformational Mutations. J. Am. Soc. Mass Spectrom. 2001, 12, 1272-1285.

15. Kaltashov, I. A.; Doroshenko, V. M.; Cotter, R. J. Gas Phase Hydrogen/Deuterium Exchange Reactions of Peptide Ions in a Quadrupole Ion Trap Mass Spectrometer. Proteins 1997, 28 , 53-58.

16. Reid, G. E.; O'Hair, R. A. J.; Styles, M. L.; McFadyen, W. D.; Simpson, R. J. Gas Phase Ion-Molecule Reactions in a Modified Ion Trap: H/D Exchange of Non-Covalent Complexes and Coordinatively Unsaturated Platinum Complexes. Rapid Commun. Mass Spectrom. 1998, 12, 1701-1708.

17. Schaaff, T. G.; Stephenson, J. L., Jr.; McLuckey, S. A. The Reactivity of Gaseous Ions of Bradykinin and Its Analogues with Hydro- and Deuteroiodic Acid. J. Am. Chem. Soc. 1999, 121, 8907-8919.

18. Schaaff, T. G.; Stephenson, J. L., Jr.; McLuckey, S. A. Gas Phase $\mathrm{H} / \mathrm{D}$ Exchange Kinetics: DI versus $\mathrm{D}_{2} \mathrm{O}$. J. Am. Soc. Mass Spectrom. 2000, 11, 167-171.

19. Reyzer, M. L.; Brodbelt, J. S. Gas-Phase H/D Exchange Reactions of Polyamine Complexes: $(\mathrm{M}+\mathrm{H})^{+},(\mathrm{M}+$ Alkali $\left.\mathrm{Metal}^{+}\right)$, and $(\mathrm{M}+2 \mathrm{H})^{2+}$. J. Am. Soc. Mass Spectrom. 2000, 11, 711-721.

20. (a) Hofstadler, S. A.; Sannes-Lowery, K. A.; Griffey, R. H. Enhanced Gas-Phase Hydrogen-Deuterium Exchange of Oligonucleotide and Protein Ions Stored in an External Multipole Ion Reservoir. J. Mass Spectrom 2000, 35, 62-70. (b) Hofstadler, S. A.; Sannes-Lowery, K. A.; Griffey, R. H. A Gated-Beam Electrospray Ionization Source with an External Ion Reservoir. A New Tool for the Characterization of Biomolecules Using Electrospray Ionization Mass Spectrometry. Rapid. Commun. Mass Spectrom 1999, 13, 1971-1979.

21. Witt, M.; Fuchser, J.; Baykut, G. In-Source H/D Exchange and Ion-Molecule Reactions Using Matrix Assisted Laser Desorption/Ionization Fourier Transform Ion Cyclotron Resonance Mass Spectrometry with Pulsed Collision and Reaction Gases. J. Am. Soc. Mass Spectrom. 2002, 13, 308-317.

22. Gill, A. C.; Jennings, K. R.; Wyttenbach, T.; Bowers, M. T. Conformations of Biopolymers in the Gas Phase: A New Mass Spectrometric Method. Int. J. Mass Spectrom. 2000, 195/196, 685-697.

23. Wyttenbach, T.; von Helden, G.; Bowers, M. T. Gas-Phase Conformation of Biological Molecules: Bradykinin. J. Am. Chem. Soc. 1996, 118, 8335-8364.

24. Counterman, A. E.; Valentine, S. J.; Srebalus, C. A.; Henderson, S. C.; Hoaglund, C. S.; Clemmer, D. E. High-Order Structure and Dissociation of Gaseous Peptide Aggregates that are Hidden in Mass Spectra. J. Am. Soc. Mass Spectrom. $1998,9,743-759$. 
25. Ling, Y.; Rodriquez, C. F.; Guo, Y.; Chu, I. K; Javahery, G.; Mak, W. A.; Hopkinson, A. C.; Siu, K. W. M. Structures and Energetics of Triply-Protonated Bradykinin. Proceedings of the 49th ASMS Conference on Mass Spectrometry and Allied Topics; Chicago, IL, May, 2001; WODam10:55.

26. Schnier, P. D.; Price, W. D.; Jockusch, R. A.; Williams, E. R. Blackbody Infrared Radiative Dissociation of Bradykinin and Its Analogues: Energetics, Dynamics, and Evidence for SaltBridge Structures in the Gas Phase. J. Am. Chem. Soc. 1996, 118, 7178-7189.

27. Price, W. D.; Schnier, P. D.; Williams, E. R. Tandem Mass Spectrometry of Large Biomolecule Ions by Blackbody Infrared Radiative Dissociation. Anal. Chem. 1996, 68, 859-866.

28. Butcher, D. J.; Asano, K. G.; Goeringer, D. E.; McLuckey, S. A. Thermal Dissociation of Gaseous Bradykinin Ions. J. Phys. Chem. A 1999, 103, 8664-8671.

29. Gimon-Kinsel, M. E.; Barbacci, D. C.; Russell, D. H. Conformations of Protonated Gas-Phase Bradykinin Ions: Evidence for Intramolecular Hydrogen Bonding. J. Mass Spectrom. 1999, 34, 124-136.

30. Zhang, Z.; Li, W.; Guan, S.; Marshall, A. G. Higher-Order Structure of Gas-Phase Peptides from Gas-Phase H/D Exchange Experiments. Proceedings of the 44th ASMS Conference on Mass Spectrometry and Allied Topics; Portland, OR, 1996; $\mathrm{p}$ 1061.

31. Wyttenbach, T.; Bowers, M. T. Gas Phase Conformations of Biological Molecules: The Hydrogen/Deuterium Exchange Mechanism. J. Am. Soc. Mass Spectrom. 1999, 10, 9-14.

32. Levy-Seri, E.; Koster, G.; Kogan, A.; Gutman, K.; Reuben, B. G.; Lifshitz, C. An Electrospray Ionization-Flow Tube Study of H/D Exchange in Protonated Bradykinin. J. Phys. Chem. A 2001, 105, 5552-5559.

33. Purves, R. W.; Barnett, D. A.; Ells, B.; Guevremont, R. GasPhase Conformers of the $[\mathrm{M}+2 \mathrm{H}]^{2+}$ ion of Bradykinin Investigated by Combining High-Field Asymmetric Waveform Ion Mobility Spectrometry, Hydrogen/Deuterium Exchange, and Energy-Loss Measurements. Rapid Commun. Mass Spectrom. 2001, 15, 1453-1456.

34. Campbell, J. M.; Collings, B. A.; Douglas, D. J. A New Linear Ion Trap Time-of-Flight System with Tandem Mass Spectrometry Capabilities. Rapid Commun. Mass Spectrom. 1998, 12, 1463-1474.

35. Collings, B. A.; Campbell, J. M.; Mao, D.; Douglas, D. J. A Combined Linear Ion Trap Time-of-Flight System with Improved Performance and $\mathrm{MS}^{\mathrm{n}}$ Capabilities. Rapid Commun. Mass Spectrom. 2001, 15, 1777-1795.

36. French, J. B. Molecular Beams for Rarefied Gasdynamic Research, North Atlantic Treaty Organization Advisory Group for Aerospace Research and Development. AGARDograph $112, \mathrm{p} 22$.

37. Wagner, D. S.; Anderegg, R. J. Conformation of Cytochrome $c$ Studied by Deuterium Exchange-Electrospray Ionization Mass Spectrometry. Anal. Chem. 1994, 66, 706-711.

38. Miranker, A.; Robinson, C. V.; Radford, S. E.; Dobson, C. M. Investigation of Protein Folding by Mass Spectrometry. FASEB J. 1996, 10, 93-101.

39. Eyles, S. J.; Dresch, T.; Gierasch, L. M.; Kaltashov, I. A. Unfolding Dynamics of a $\beta$-Sheet Protein Studied by Mass Spectrometry. J. Mass Spectrom. 1999, 34, 1289-1295.

40. Babu, K. R.; Douglas, D. J. Methanol-Induced Conformations of Myoglobin at $\mathrm{pH}$ 4.0. Biochemistry 2000, 39, 14702-14710.

41. Mao, D.; Ding, C.; Douglas, D. J. H/D Exchange of Myoglobin Ions in a Linear Quadrupole Ion Trap. Rapid Commun. Mass Spectrom. 2002, 16, 1941-1945.

42. Schuler, K. E. Reaction Cross Sections, Rate Coefficients, and Nonequilibrium Kinetics. In Chemische Elementarprozesse; Heidberg, J.; Heydtmann, H.; Kohlmaier, G. H., Eds.; SpringerVelag: New York, 1968; p 1.

43. Asano, K. G.; Goeringer, D. E.; McLuckey, S. A. Thermal Dissociation in the Quadrupole Ion Trap: Ions Derived From Leucine Enkephalin. Int. J. Mass Spectrom. 1999, 185/186/187, 207-219.

44. Blatt, R.; Zoller, P.; Holzmüller, G.; Siemers, I. Brownian Motion of a Parametric Oscillator: A Model for Ion Confinement in Radio Frequency Traps. Z. Phys. D: At. Mol. Clusters 1986, 4, 121-126.

45. Paradisi, C.; Todd, J. F. J.; Traldi, P.; Vettori, U. Boundary Effects and Collisional Activation in a Quadrupole Ion Trap. Org. Mass Spectrom. 1992, 27, 251-254.

46. Paradisi, C.; Todd, J. F. J.; Vettori, U. Comparison of Collisional Activation by the "Boundary Effect" versus "Tickle" Excitation in an Ion Trap Mass Spectrometer. Org. Mass Spectrom. 1992, 27, 1210-1215.

47. Curcuruto, O.; Fontana, S.; Traldi, P.; Celon, E. Effectiveness of the "Border Effect" for Daughter-Ion Spectrometer by IonTrap Mass Spectrometry. Rapid Commun. Mass Spectrom. 1992, $6,322-323$.

48. Creaser, C. S.; O'Neill, K. E. Boundary-Effect Activated Dissociation in Ion Trap Tandem Mass Spectrometry. Org. Mass Spectrom. 1993, 28, 564-569.

49. March, R. E.; Weir, M. R.; Londry, F. A.; Catinella, S.; Traldi, P.; Stone, J. A.; Jacobs, W. B. Controlled Variation of BoundaryActivated Ion Fragmentation Processes in a Quadrupole Ion Trap. Can. J. Chem. 1994, 72, 966-976.

50. Vachet, R. W.; Glish, G. L. Boundary-Activated Dissociation of Peptide Ions in a Quadrupole Ion Trap. Anal. Chem. 1998, 70, 340-346. 